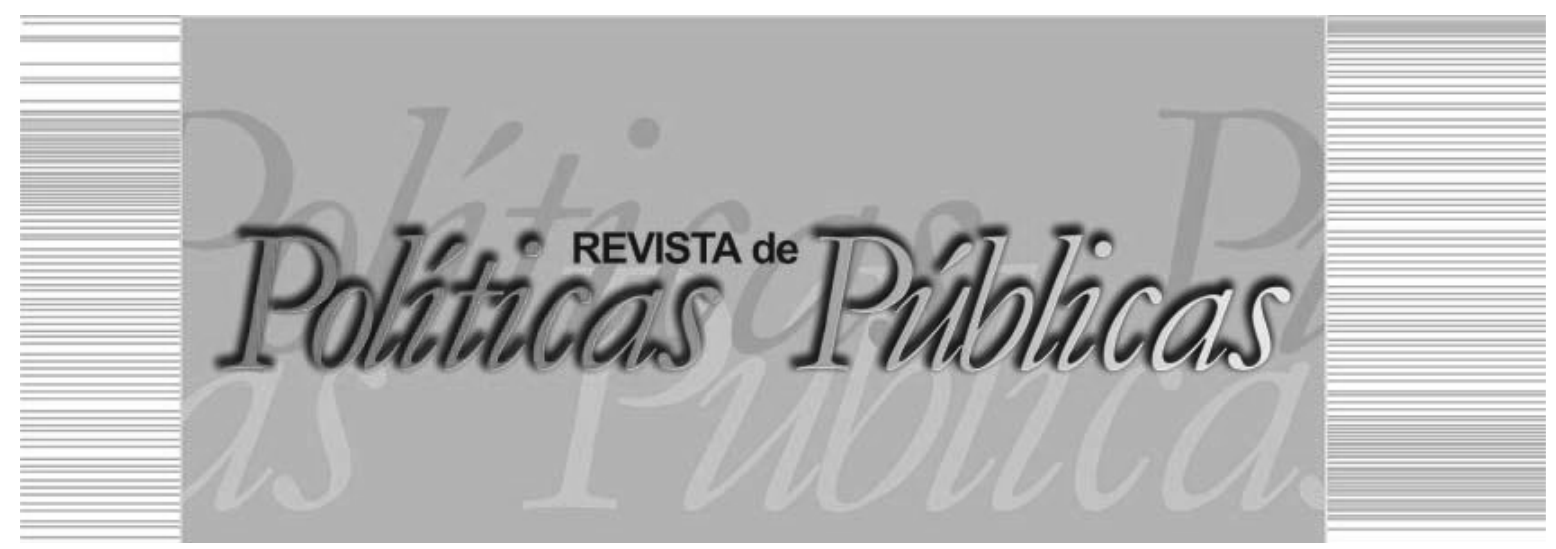

\title{
DEIXA A GIRA GIRAR: proteção e preservação do patrimônio cultural das religiões afro-brasileiras 1
}

\author{
Maria Ines Caetano Ferreira ${ }^{1}$ \\ Walkyria Chagas da Silva Santos ${ }^{2}$
}

\section{Resumo}

Este artigo analisa o processo de tombamento do Terreiro Casa Branca, buscando compreender elementos da disputa para inserção do tema da proteção e preservação do patrimônio da cultura das religiões afro-brasileiras na agenda do governo federal. Adota, como método, o estudo de formação da agenda governamental, incluindo o modelo dos múltiplos fluxos e do equilíbrio pontuado. A técnica de pesquisa tem por base a análise de documentos históricos e administrativos. Os resultados revelam as dinâmicas políticas que possibilitaram a emancipação e valorização das religiões afro-brasileiras, a despeito dos aspectos hierárquicos e autoritários da sociedade brasileira. Contudo, apesar do triunfo de concepções mais democráticas, mantém-se as ameaças na implementação e manutenção das conquistas dos movimentos negros e militantes da cultura afro-brasileira.

Palavras-chave: Tombamento, religião afro-brasileira, cultura afro-brasileira, políticas públicas, formação da agenda

\footnotetext{
Bacharel em Ciências Sociais, Doutora em Sociologia pela Universidade de São Paulo (USP), Professora Adjunta da Universidade Federal do Recôncavo da Bahia (UFRB). E-mail: inesferreira@ufrb.edu.br/Endereço: Universidade Federal do Recôncavo da Bahia - UFRB: Rua Irineu Sacramento, S/N, Centro - Cachoeira. CEP: 44300-000

2 Graduada em Direito, Doutoranda em Direito pela Universidade de Brasília (UnB) e em Estado e Sociedade pela Universidade Federal do Sul da Bahia (UFSB). E-mail: kyriachagas@yahoo.com.br / Endereço: Universidade Federal do Sul da Bahia - UFSB: Rodovia de Acesso para Itabuna, km 39 - Ferradas, Itabuna - BA, 45613-204
} 
LET THE "GIRA" SPINS: legal protection and preservation of the cultural inheritance of the Afro-Brazilian religious

\begin{abstract}
This article analyses the process of the institute of the "tombamento" (legal protection to the cultural of inheritance) of Terreiro Casa Branca. This work investigates elements of the struggle to bring the legal protection of the Afro Brazilian cultural inheritance onto the federal government agenda. It was adopted the methodology of the analyses of the agenda setting, as multiple streams and the punctuated equilibrium. The technical used was the analyses of the administrative and historical documents. Findings show political disputes that became possible the emancipation and valorization of the Afro-Brazilian religions, despite the hierarchical and authoritarian elements of the Brazilian society. Although, democratic conceptions were triumphed, it is remained threats for the implementation and keeping the achievements of the black social movements and activists of Afro-Brazilian culture.

Key words: Legal proctection of cultural inheritance, Afro-Brazilian religion, Afro-Brazilian culture, public policies, agenda setting.
\end{abstract}

\title{
1 INTRODUÇÃO
}

Este trabalho analisa a inserção da Política de Proteção e Preservação do Patrimônio Cultural das Religiões de Afro-brasileiras na agenda do governo na década de 1980, a qual é instrumentalizada a partir do tombamento de espaços religiosos afro-brasileiros, pelo Instituto do Patrimônio Histórico e Artístico Nacional (IPHAN).

O problema de pesquisa que inspira o presente artigo é entender o porquê de a política cultural ter sido inaugurada no Brasil na década de 1930 e, somente na década de 1980 é que monumento negro foi objeto de proteção estatal, com o tombamento do Ilê Axé Iyá Nassô Oká (Terreiro da Casa Branca). Como ocorreu tal proteção? De que forma ocorreu a inserção da proteção dos espaços religiosos afro-brasileiros na agenda governamental?

O governo federal tombou nove terreiros; oito deles estão na Bahia - Ilê Axé Iyá Nassô Oká (Terreiro da Casa Branca); Ilê Axé Opô Afonjá; Ilê iyá Omi Axé Iyamassê (Terreiro do Gantois); Manso Banduquenqué (Bate Folha); Ilê Maroiálaji Alakêto; Ilê Axé Oxumarê - todos em Salvador/BA; ZoogodoBogum Malê Seja Undé (Terreiro Roça do Ventura) em Cachoeira/BA e o Omo Ilê Agbôula, na Ilha de Itaparica/BA - e um no Maranhão, o Casa Grande de 
DEIXA A GIRA GIRAR: proteção e preservação do patrimônio cultural das religiões afro-brasileiras

Minas ou Casa das Minas Jeje ou Querebentã de Zomadonu². O primeiro pedido de tombamento em nível nacional foi iniciado formalmente em 1982 e concluído em 1986.

$\mathrm{O}$ estudo da agenda governamental busca reconhecer a articulação de variáveis envolvidas no processo de inserção de um determinado tema nas preocupações e ações do governo, considerando que raramente o governo se abre para novos temas. Mais especificamente, o objetivo deste artigo é compreender as disputas envolvidas no processo do tombamento do Terreiro da Casa Branca, considerando tratar-se de uma vitória da luta do povo negro pelo reconhecimento de sua participação no processo de formação da sociedade brasileira. A elucidação das disputas desse movimento revela os aspectos hierárquicos e autoritários da sociedade brasileira e insinua como, em determinados momentos históricos, foi possível o triunfo de concepções mais democráticas.

Essa pesquisa se ancorou em três modelos teóricos, dos Múltiplos Fluxos, desenvolvido por Kingdon (1995, 2006a, 2006b), do equilíbrio pontuado de Baumgarter e Jones (1993) e o apresentado por Cobb e Elder (1971). A metodologia envolveu estudo de documentos históricos e administrativos, sobretudo nas informações apresentadas nas páginas do Processo ${ }^{\circ}$ 1.067-T-82, referente ao tombamento do Ilê Axé Iyá Nassô Oká (Terreiro da Casa Branca), primeiro processo de tombamento de terreiro de candomblé analisado pelo IPHAN.

Os resultados revelam dinâmicas que embaraçam os processos de emancipação e valorização das religiões afro-brasileiras na esfera da tomada de decisão dos governos. Vale ressaltar que tais dinâmicas se ancoram em argumentos que prestigiam aspectos associados a padrões estéticos europeus, mais diretamente conectados aos costumes e arquitetura cristã. Ressalte-se que a predileção dos elementos associados às religiões cristãs se justifica formalmente por critérios técnicos e não pelo preconceito latente contra as religiões afro-brasileiras. Curiosamente essa emancipação parece ser instituída em períodos de governo autoritário, por força da ação de agentes no governo, contraditoriamente impulsionados por visão tolerante e democrática. Contudo, as ações de governo comprometidas com o avanço de direitos no exercício dos adeptos das religiões afro-brasileiras não se consolidam em virtude da oposição de grupos 
conservadores ou pela fragilidade no modo de implementação das ações, pelo próprio governo.

O texto se divide em cinco itens. O primeiro discute a segregação contra o negro e as religiões trazidas da África. O segundo apresenta informações sobre o princípio das políticas culturais no país. O terceiro discorre sobre os modelos de análise da formação da agenda governamental, o quarto analisa a formação da agenda a partir dos dados levantados na pesquisa, com destaque para o processo administrativo de tombamento do Ilê Axé Iyá Nassô Oká (Terreiro da Casa Branca). O último interpreta o cenário social das variáveis que influenciaram para que os múltiplos fluxos, apresentados no modelo de Kingdon, confluíssem para a realização do tombamento do Ilê Axé Iyá Nassô Oká (Terreiro da Casa Branca), a primeira aplicação da proteção e preservação do patrimônio cultural para espaço religioso afro-brasileiro pelo governo federal.

\section{O ESTADO E A PERSEGUIÇÃO ÀS RELIGIÕES AFRO- BRASILEIRAS: breve relato}

A escravatura é uma das razões para a ausência de entendimento por parte do Estado brasileiro em relação à cosmovisão das religiões afro-brasileiras. A estrutura social dos negros na África não foi reproduzida no Brasil devido à opressão do período. Entretanto, a partir da reconstrução das estruturas na África em miniatura $^{3}$ os negros em situação de diáspora conseguiram reconstruir e remodelar suas estruturas sociais. O Estado foi e é agente central na segregação dos negros e marginalização das religiões afro-brasileiras, legitimando práticas discriminatórias desde os tempos coloniais. Isso se manifesta na ambiguidade implícita das legislações que envolvem o tema da religiosidade. No período colonial, o Direito Alienígena segregou a população nativa e os africanos escravizados. (CRISTIANI, 2005). Com a mudança da Família Real para o país, celebrou-se entre Portugal e Inglaterra o Tratado do Comércio e Navegação ${ }^{4}$, que garantiu liberdade de consciência e licença para celebração de culto para os ingleses no Brasil, mas vedando-a para índios e negros. (RIBEIRO, 2002). O Estado se amalgamava à religião Católica, a qual justificava a escravidão, que iria salvar as almas dos povos de deuses pagãos. (SANTOS, 2009). No Império, a Constituição de 1824 proibiu a perseguição por motivos religiosos, contudo, reconheceu como oficial a Religião Católica 
DEIXA A GIRA GIRAR: proteção e preservação do patrimônio cultural das religiões afro-brasileiras

Apostólica Romana e ainda limitou o culto das demais religiões ao âmbito doméstico. (BRASIL, 1824).

A primeira Constituição republicana, em 1891, extinguiu a religião oficial de Estado e garantiu formalmente a liberdade de culto no país. (BRASIL, 1891). Apesar de a liberdade de culto constar no texto constitucional, no mundo do $\operatorname{ser}^{5}$ ocorreu pouca ou nenhuma mudança na perseguição aos praticantes de religiões afro-brasileiras, posto que os Códigos de Posturas ${ }^{6}$ disciplinavam o que era ou não permitido aos munícipes. Assim, os ajuntamentos de negros, batuques, lundos e candomblés eram proibidos pelos Códigos de Posturas e denunciados pela imprensa local. (SÁ, 2011; SANTOS, 2009). Destaque-se que o curandeirismo e a feitiçaria, práticas associadas às religiões afro-brasileiras, foram proibidos e criminalizados nos artigos 156, 157 e 158, do Código Criminal Republicano de 1890. (CHEHOUD, 2012).

As Constituições subsequentes de 1934, 1937, 1946, 1967 e 1988 mantiveram a separação entre Estado e Igreja, garantindo a laicidade ou secularidade estatal ${ }^{7}$. Mas por quase todo o século XX persistiram a discriminação e perseguição, inclusive policial, cotidiana contra os adeptos de religiões afro-brasileiras. Segundo o discurso civilizador e higienista, era necessário desafricanizar o Brasil, livrar o país dos costumes primitivos. (SANTOS, 2009; SODRÉ, 2010).

Somente a partir da Constituição de $1988^{8}$ o direito à liberdade religiosa foi garantido, sem salvaguardas para a ingerência estatal no exercício do direito individual do cidadão, em defesa da ordem pública e aos bons costumes. A Constituição Federal (CF) de 1988 trouxe uma nova concepção para outros temas importantes na discussão da preservação do patrimônio cultural das religiões afro-brasileiras, tais como os direitos culturais e patrimônio cultural.

$\mathrm{O}$ art. $216^{\circ}$ garante a proteção do patrimônio material e imaterial, referência para o processo de formação da sociedade brasileira, resguardando a identidade e memória. No $1^{\circ}$, do mesmo artigo, são apresentados os instrumentos de proteção que deverão ser promovidos pelo Estado com a colaboração da comunidade, são eles: inventários, registros, vigilância, tombamento e desapropriação, e outras formas de acautelamento e preservação. (BRASIL, 2010). Entre eles, o tombamento é o instrumento mais demandado pelos terreiros para assegurar a continuidade dos espaços religiosos e manifesta- 
ções culturais e religiosas guardadas dentro dos Ilês Axés. Por esse motivo, ele é o objeto deste estudo.

Qual o significado de patrimônio cultural e direitos culturais ${ }^{9}$ para a Constituição brasileira atual? Os direitos culturais ${ }^{10}$, consagrados no art. 215 da CF, são parte dos direitos fundamentais, posto que decorrem do regime e princípios constitucionais e de tratados internacionais, dos quais o Brasil é signatário. Tais direitos exigem atuação positiva do Estado que se traduz em ações de política cultural oficial. (SILVA, 2001; ZANDONADE, 2012).

A partir da leitura do art. $215^{\circ}$, compreende-se que o Estado garantirá os direitos culturais e protegerá as manifestações culturais dos grupos participantes do processo de formação da sociedade brasileira. Portanto, reconhece que a sociedade brasileira é multicultural e que a contribuição dos povos que participaram da formação da nação brasileira deve ser preservada para que as futuras gerações usufruam de sua memória e identidade. (BRASIL, 2010).

José Afonso da Silva (2001, p. 101) compreende que a concepção de patrimônio cultural não está atrelada unicamente à questão histórica, mas, "[...] abrange todas as expressões simbólicas da memória coletiva, constitutivas da identidade de um lugar, uma região e uma comunidade". Até a década de 1980 o Estado brasileiro não havia individualizado nenhum monumento negro como patrimônio cultural nacional. A inovação na forma de pensar patrimônio cultural foi iniciada com o tombamento Ilê Axé Iyá Nassô Oká (Terreiro da Casa Branca) em 1986, mas a sua garantia só foi formalizada na Constituição de 1988.

As modificações ocorridas no texto constitucional de 1988 resultaram das seculares lutas dos negros e do povo de santo na busca por reconhecimento pelo Estado brasileiro de sua condição de sujeito e não de objeto. Na década de 1980, os negros buscaram as garantias e os direitos até então negados, participando das discussões para elaboração do texto constitucional e das sessões da Assembleia Constituinte de 1985. Um dos grandes momentos de luta por garantia de direitos está relatado nas páginas do Processo $\mathrm{n}^{\circ} 1.067$ T-82, pois o tombamento do Ilê Axé Iyá Nassô Oká não significou apenas ruptura com a antiga forma de pensar patrimônio pelo Estado brasileiro, mas também simbolizou a vitória do povo negro pelo reconhecimento e a inserção da proteção e preservação do patrimônio cultural das religiões afro-brasileiras na agenda governamental. 
DEIXA A GIRA GIRAR: proteção e preservação do patrimônio cultural das religiões afro-brasileiras

\section{POLÍTICAS CULTURAIS NO BRASIL}

As políticas culturais foram inauguradas no Brasil apenas na década de 1930, posto que, durante os períodos anteriores, não houve intervenções conjuntas e sistemáticas, com atores coletivos e metas. No Império e na $1^{\mathrm{a}}$ República as ações tinham cunho elitista, hostilizando e marginalizando as manifestações populares, embora algumas delas tenham resistido à hegemonia branca e europeizada, como o samba, a capoeira e o maracatu. (ALBUQUERQUE JÚNIOR, 2007; RUBIM, 2007). As políticas culturais tomaram forma principalmente no segundo governo de Vargas, quando as manifestações populares foram legitimadas e convertidas em símbolos nacionais, embora, de forma autoritária, já que com a intervenção e validação estatal (ALBUQUERQUE JUNIOR, 2007; RUBIM, 2007).

A necessidade de preservar o patrimônio cultural representativo da nação apareceu na década de 1920, mas só foi institucionalizada em 1937 com a criação do Serviço do Patrimônio Histórico e Artístico Nacional (SPHAN1), que priorizou a preservação do patrimônio da cultura branca e elitizada e a estética barroca, a despeito de diversas contestações. (RUBIM, 2007). O SPHAN1 fazia parte das instituições de memória, posto que foi criado para materializar uma história nacional, a "[...] construção da "nação brasileira', por meio da produção de discursos em busca das raízes e origens da nação." (CHUVA, 2011, p. 43). Mas, então, qual seria o tipo de patrimônio que representaria a nação brasileira? A grande quantidade de bens tombados representava a produção artística e arquitetônica do período colonial, com ênfase para o patrimônio da região de Minas Gerais, tendo sete cidades tombadas.

Os tombamentos ocorreram combinados com a publicação de livros que falavam sobre as raízes fundadoras da nacionalidade brasileira, como Casa Grande e Senzala e Raízes do Brasil. Assim, o SPHAN1 visava que a história do Brasil fosse compreendida a partir da leitura da cultura material que era tombada pelo órgão, e a ênfase no patrimônio de origem portuguesa "[...] é explicada em função da força da sua cultura material, em detrimento da fragilidade material da cultura indígena ou da presença africana, em função da sua condição escrava." (CHUVA, 2011, p. 44).

Assim, a arquitetura de origem portuguesa foi selecionada como aquela que representaria as origens da nação, especialmente as construções religiosas, por atender aos critérios básicos que norte- 
avam a ação do SPHAN, as construções religiosas possuíam beleza e verdade, tendo como essência a qualidade construtiva. (CHUVA, 2011).

No período democrático de 1945 e1964 ocorreram poucas ações estatais na área da cultura. No governo militar, as políticas culturais podem ser divididas em três momentos diferentes: o primeiro, de 1964-1968, marcado por movimento notadamente de esquerda e pela criação de secretarias estaduais de cultura; o segundo momento, de 1968-1974, pela forte violência contra os opressores e pelo vazio cultural; o terceiro e último momento, de 1974 a 1985, consistiu na transição da ditadura para democracia, com a criação de instituições culturais. Vale destacar a atuação de Aloísio Magalhães, que, em 1979, assumiu a Secretaria do Patrimônio Histórico e Artístico Nacional (SPHAN2). Ele criou organismos, como a Fundação Nacional Pró-Memória, refutou a concepção de bens culturais e patrimônio até então vigente. (RUBIM, 2007). Os questionamentos sobre proteção e preservação do patrimônio cultural das religiões afro-brasileiras ganharam visibilidade a partir desse momento.

\section{FORMAÇÃO DA AGENDA GOVERNAMENTAL: modelos}

A formação da agenda é a fase na qual os grupos sociais debatem os problemas que os afetam e concorrem entre si para sensibilizar os tomadores de decisão da necessidade da ação do governo em relação ao seu tema, o qual, então, converte-se em questão pública. A opção pelo debate sobre a formação da agenda se justifica pelo fato de desvendar os paradigmas válidos nas relações entre Estado e sociedade, os jogos de força e a construção da hegemonia de grupos sociais, assim como das formas de resistência e enfrentamento.

Como já informado, esse estudo se apoiou nas vertentes de Kingdon, Baumgartem e Jones e Cobb e Elder. Para John Kingdon (1995) agenda é a fase que estabelece uma lista de problemas que despertam a atenção dos cidadãos e do governo. Ela se divide em três tipos. A sistêmica, caracterizada por preocupações da sociedade que não despertam atenção do governo; a governamental, composta por questões que chamam atenção do governo; a terceira, decisional, que reúne algumas questões da agenda de governo prontas para se tornarem ação. Poucos são os problemas da agenda sistêmica que ingressam na agenda decisional. Kingdon busca compreender o complexo processo da marcha da conversão de problemas da so- 
DEIXA A GIRA GIRAR: proteção e preservação do patrimônio cultural das religiões afro-brasileiras

ciedade em questões da agenda decisional. Essa conversão requer a combinação de três diferentes fluxos. O primeiro deles é o fluxo dos problemas, que envolve a percepção e experiência de uma questão. Nesse fluxo os atores despertam para uma situação social que os incomoda por meio de três mecanismos, a saber: indicadores (informações que permitem caracterizar um quadro social), eventos dramáticos e crises (que enternecem para uma determinada situação) e feedback de ações de governo (que envolve a acumulação de informações e experiências). Esses três mecanismos influenciam na interpretação da situação, inclusive na possível percepção favorável dos formuladores de políticas.

O segundo fluxo é o das alternativas, que envolve a elaboração de soluções, de estratégias para conceituar o problema e propor a forma de ação do governo. Essas elaborações desenvolvidas em comunidades de políticas, compostas por grupos de especialistas - como assessores, acadêmicos, consultores, parlamentares etc. -, competem entre si no movimento de persuadir o governo sobre o acerto de suas propostas. No processo de persuasão ocorre difusão de ideias, para multiplicação de adeptos. As alternativas mais viáveis, inclusive em relação aos valores predominantes no cenário social e governamental, geralmente são as escolhidas.

O terceiro fluxo é o político, que diz respeito a partidos políticos, eleições, forças organizadas e disposições sociais. Os políticos tendem a seguir a posição de um consenso entre as forças organizadas, evitando conflitos. Aqui o humor nacional pode apoiar ou rejeitar um tema. As forças políticas organizadas estimulam ou impõem pressões aos temas. Vale ressaltar que a agenda de comunidades políticas relacionadas a amplos contextos predominam sobre aquelas com vínculos apenas locais. Kindgon (1995) ainda chama atenção para as mudanças dentro do governo, eleições, início de governo, alterações em posições estratégicas em desenhos institucionais, que favorecem a inserção de novos temas na agenda governamental.

As mudanças na agenda do governo ocorrem quando há convergência dos três fluxos, ou seja, quando a percepção sobre um tema é positiva, ao mesmo tempo há uma solução aceitável e o ambiente político é propício. Essa situação é uma janela de oportunidade, fenômeno raro, de curta duração. A atuação do empreendedor de políticas é central nas situações de janelas de oportunidade. Ele pode ser, ou não, do governo, mas deve estar envolvido com a ques- 
tão, disposto a investir e integrar os três fluxos para emplacá-la. Há ainda os atores visíveis e invisíveis. Entre os visíveis destacam-se o presidente, ministros, secretários-executivos, parlamentares, que atuam no fluxo dos problemas. Os atores invisíveis contribuem com o fluxo de alternativas, são eles: assessores, acadêmicos, especialistas, consultores etc. Todas essas personagens interferem no cenário da formação da agenda apoiando ou impondo obstáculos para a aceitação de uma questão.

O modelo de equilíbrio pontuado de Baumgarter e Jones (1993) salienta o fenômeno dos longos períodos de estabilidade na agenda, esclarecendo mecanismos que impõem obstáculos à introdução de novos temas na agenda. Esses autores distinguem dois sistemas de governo, a saber: o macro, ocupado pelas lideranças; e, o subsistema, formado por comunidades de especialistas e agentes que detêm o monopólio sobre a concepção e valores (o tom) das políticas e, também, sobre sua execução. O subsistema é conservador, esforça-se para resguardar as concepções de políticas vigentes, uma vez que participaram de sua instituição. A possibilidade de mudanças nas concepções e, consequentemente, no modelo de políticas é mais propícia por meio de intervenções do macrossistema, no qual se encerram agentes não comprometidos com as concepções de políticas vigentes. As mudanças materializadas no macrossistema incidem sobre o subsistema. Conquanto, essas mudanças são raras, predominando longos períodos de estabilidade.

Por fim, o modelo de Cobb e Elder (1971) consiste da agenda sistêmica - que envolve problemas da sociedade, abordados de forma geral e abstrata - e da institucional - abrangendo questões consideradas pelo governo e com abordagem organizada, concreta, encaminhada para a ação governamental. $\mathrm{O}$ processo da formação da agenda envolve o dilatamento do debate e do conflito dos temas, despertando a atenção do público, principalmente do setor mais bem informado. Segundo os autores, os temas da agenda sistêmica com maior expressão social, definidos de modo mais simples, têm mais apelo para o ingresso na agenda institucional. Cobb, Ross e Ross (1976) abordam a transição dos temas da agenda sistêmica para a institucional, assim como o contrário. Neste último caso, os temas são articulados dentro do próprio governo, por isso mesmo têm mais facilidade para serem inseridos na agenda institucional, podendo expandir-se para a sistêmica, com o objetivo de buscar a legitimidade da ação governamental. A distância entre as agendas sistêmica e 
DEIXA A GIRA GIRAR: proteção e preservação do patrimônio cultural das religiões afro-brasileiras

institucional informam o nível de democracia da sociedade; quando próximas, trata-se de contexto democrático; se distantes, trata-se de ambiente social hierárquico, com governo afastado do debate com a sociedade.

Outro conceito relevante é o da não-ação, ou de como evitar que um problema ganhe destaque e se converta em questão. Na realidade, esse é um processo mais comum do que o surgimento das janelas de oportunidades, sobretudo em sociedades hierarquizadas. Bachrach e Baratz (2011) argumentam que há duas faces do poder, uma, mais aberta à manifestação dos conflitos; a outra, menos perceptível, caracterizada pela supressão dos conflitos. Os formuladores de políticas buscam levar para a decisão somente questões seguras, abortando tentativas que possam representar alguma ameaça. Os primeiros obstáculos impostos visariam impedir que o problema ganhasse visibilidade pública. Se essa estratégia falhar, procura-se combater a quase questão na fase de definição de alternativas para garantir formas que dificultem mudanças no cenário, mesmo com as novas ações governamentais.

\section{O PROCESSO DE TOMBAMENTO DO ILÊ AXÉ IYÁ \\ NASSÔ OKA: uma análise sobre a formação da agenda}

O uso da metodologia da formação da agenda propicia a caracterização de processos envolvidos na discriminação contra as religiões afro-brasileiras, assim como os possíveis caminhos para o reconhecimento de sua legitimidade, construídos no decurso de sua inserção na agenda governamental.

O prestígio atribuído aos elementos associados à cultura dos colonizadores europeus, em detrimento da dos negros, descortina o elemento autoritário e hierárquico predominante no Brasil. O reconhecimento da cultura negra, incluindo a liberdade de crença e culto, não foi tema da agenda de governo até a década de 80. Associada à repressão, a falta de ações governamentais em relação ao tema remete à estratégia da não-ação, pela qual as autoridades evitaram o debate de problemas indesejados, impedindo-os de competir pelo ingresso na agenda, como apontam Bachrach e Baratz (2011). A longevidade da repressão ao reconhecimento do valor da cultura negra alude ao monopólio de concepções (imagens e tom) das políticas por parte dos agentes que ocuparam o subsistema, como ensinam Baumgarter e Jones (1993). Essas imagens de políticas, fartas de in- 
formações e emoções autocráticas, hierárquicas e discriminatórias, integradas a valores europeus, obstruíram a legitimação da cultura negra.

Insolitamente, o reconhecimento da legitimidade da cultura negra se deu pelo próprio governo, na gestão Vargas e no regime militar, ambos autoritários. Com Vargas, a identidade brasileira se fundamentou em elementos da cultura nacional, incorporando referências da cultura negra. Desse modo, embora os movimentos negros sempre tenham lutado pela legitimação de sua cultura, foi pela ação do governo que, ao buscar legitimar-se sobre uma imagem de brasilidade, o tema da legitimidade da cultura negra se impôs. Trata-se aqui de exemplo da agenda institucional penetrando na sistêmica, em busca de legitimação.

Norteando-se pela teoria do equilíbrio pontuado, conclui-se que, após longo período de estabilidade nos valores dominantes da cultura, que guiaram a ação e a não-ação do governo, o macrossistema propiciou transformações na área cultural, empreendidas por um governo poderoso. Mas esse movimento de abertura esmoreceu ao longo dos governos seguintes - retornando à estabilidade de um subsistema com concepções autocráticas e hierárquicas -, tendo sido retomado apenas no final do regime militar. Assim, após curto período de mudança, retornou-se ao longo estado de estabilidade em relação à imagem da política, que obstruía os canais para a inserção das demandas de proteção e preservação do patrimônio cultural das religiões afro-brasileiras na agenda do governo.

As mudanças efetuadas no final do regime militar foram profundas. Esse movimento aconteceu em tempos de crise do governo militar, quando o humor político favoreceu a abertura para a consideração das demandas das religiões afro-brasileiras. De qualquer modo, deve-se salientar a forma autoritária como a agenda institucional acolheu a demanda da proteção e preservação do patrimônio cultural das religiões afro-brasileiras, instrumentalizada na política de tombamento de terreiros.

A interpretação do tombamento do terreiro da Casa Branca pelo modelo de Kingdon permite reconhecer elementos que favoreceram a conquista do direito da preservação das religiões afro-brasileiras. 
A vigorosa atuação de Aloísio Magalhães para as mudanças em relação às ideias sobre cultura e preservação - no período em que ocupou a direção do órgão federal de patrimônio, em 1979, e, depois, a secretaria da cultura do Ministério da Educação e Cultura, em 1981 - é um exemplo do fluxo da percepção dos problemas, quando ocorrem sensibilização e mutações na percepção de temas. Magalhães influenciou no engrandecimento da noção de bens culturais, a fim de que fosse agregada a cultura popular. Desse modo, a concepção do que poderia ser classificado como patrimônio cultural - antes limitada a conjuntos arquitetônicos de origem europeia e branca - foi estendida, abrindo caminho para a proteção e preservação dos terreiros de candomblé. (PEREGRINO, 2014). A partir de então a discussão sobre preservação de terreiros entrou para a agenda governamental.

Os mecanismos ligados à sensibilização do problema, apresentado por Kingdon, são aqui verificados. No caso específico da capital baiana, as conversões em relação à relevância da proteção dos terreiros foram fortalecidas pelo mecanismo dos indicadores. Isso porque a SPHAN-FNPM firmou convênio com a Fundação Cultural do Estado da Bahia (FUNCEB) e a Prefeitura Municipal de Salvador para realização do Mapeamento dos Sítios e Monumentos Religiosos Negros da Bahia (MAMNBA), coordenado por Ordep Serra, que revelou o grande número de terreiros existentes e mapeados na capital baiana. Somaram-se ao mapeamento as informações produzidas pelo inventário de 1982, que identificou os bens culturais de origem africana localizados no Estado da Bahia, estimando a existência de cinco mil terreiros de candomblé em todo o Estado, dois mil deles, na capital. (ZAMBUZZI, 2010). Identificaram-se terreiros que poderiam desaparecer por causa de especulação imobiliária, violência e degradação do imóvel. Especialmente a situação do Ilê Axé Iyá Nassô Oká (Terreiro da Casa Branca) era temerosa; sua continuidade estava ameaçada devido ao arrendamento de partes do terreno pelo proprietário, pelo funcionamento de um posto de gasolina no espaço do terreiro e, ainda, pelo risco de desabamentos. (SERRA, 2005). $\mathrm{O}$ egbé ${ }^{11}$ Iyá Nassô via ameaçada toda a herança ancestral depositada em árvores, solo, fontes e outros locais sagrados devido ao Axé, que fora depositado pelas suas fundadoras, por volta de 1830 . $\mathrm{O}$ espaço de culto de origem africana da nação Keto, considerado o mais antigo do Brasil, corria risco de diminuição. (INSTITUTO DO PATRIMÔNIO HISTÓRICO E ARTÍSTICO NACIONAL, 1982). 
Isso poderia impedir o acesso das futuras gerações a todo o legado ancestral depositado material e imaterialmente no Terreiro da Casa Branca. Todas essas informações fundamentaram os argumentos dos defensores do tombamento dos terreiros, na busca de convencerem novos adeptos para a causa.

O mecanismo da disseminação das ideias e convencimento do público foi feita pela mídia baiana, que difundiu essas informações, descortinando a insegurança social da comunidade do Terreiro Casa Branca e suas implicações diretas na vida de todo povo de santo. O mecanismo do feedback de ações já implementado pelo governo se exemplifica nas contestações dos representantes do SPHAN/FNPM e de participantes do projeto MAMNBA em relação às políticas culturais praticadas até então, por desfavorecerem a cultura das camadas populares.

Em resumo, a identificação desses mecanismos indica como foi possível promover a sensibilização em relação a um problema que, até então, tinha frágil apelo para a agenda governamental.

Os relatos de Velho (2009) e de Serra (2005) descortinam os movimentos do segundo fluxo de Kingdon, ligado à escolha de alternativa para a elaboração da política. As comunidades de políticas se encontraram em reuniões para discutir a melhor alternativa para assegurar a preservação do Terreiro da Casa Branca. (INSTITUTO DO PATRIMÔNIO HISTÓRICO E ARTÍSTICO NACIONAL, 1982). Alguns técnicos e outros participantes contestaram o instituto do tombamento para a preservação de um terreiro. Fato que demonstra ter sido necessária muita persuasão para a aprovação do tombamento do terreiro, ainda que, por quantidade mínima de votos.

Os debates da Reunião de Conselheiros e Técnicos do SPHAN, em 1983, com o assunto Apreciação técnica da proposta de preservação do Terreiro da Casa Branca, Bairro do Engenho Velho em Salvador-BA, ilustram o árduo processo da sensibilização. Na ata constata-se a oposição dos técnicos à preservação do terreiro, justificada pelos princípios que fundamentavam o tombamento de bens de origem europeia, de cultura branca. Segundo esses princípios, o tombamento visaria preservar o bem, enquanto algo imutável, contrastando com o dinamismo das manifestações culturais dos espaços religiosos afro-brasileiros, onde, em caso de expansão na quantidade de frequentadores, pode-se ampliar o número de casas, 
para o acondicionamento dos fundamentos de culto. Assim, embora os técnicos tenham reconhecido o significativo valor cultural do sítio, eles introduziram objeções à preservação, em virtude da especificação dos bens e seu conteúdo, que era incompatível com o padrão aplicado aos bens de inspiração europeia. (INSTITUTO DO PATRIMÔNIO HISTÓRICO E ARTÍSTICO NACIONAL, 1982).

Os técnicos concluíram pela necessidade de procedimentos para garantir a permanência da manifestação cultural: a) garantia de posse para o grupo religioso no local atual; b) obras de emergência no local que possibilitem a continuidade dos trabalhos religiosos. Tais medidas visavam neutralizar as principais ameaças: a) possível expulsão do grupo do local pelo proprietário da área, fazendo valer o seu direito de domínio; b) o iminente perigo de desabamento; e, c) a impossibilidade de se tombar, sem a desapropriação do sítio. As inúmeras dúvidas levaram à decisão de que: a) o tombamento não devia ser proposto naquele momento, posto que havia dúvidas se era o mais adequado; $b$ ) remeter o processo ao Conselho Consultivo da SPHAN para que se pronuncie sobre o valor cultural do bem e a forma mais compatível para preservação. (INSTITUTO DO PATRIMÔNIO HISTÓRICO E ARTÍSTICO NACIONAL, 1982).

Segundo o relator do processo, Gilberto Velho, (INSTITUTO DO PATRIMÔNIO HISTÓRICO E ARTÍSTICO NACIONAL, 1982), os membros do conselho entendiam como equivocado o tombamento de algo, que, na opinião deles, era desprovido de edificações que tivessem valor artístico, a exemplo da suntuosidade das "[...] edificações religiosas, militares e civis da tradição luso-brasileira." (VELHO, 2012). Os conselheiros concordavam com a proteção, mas não com o tombamento do terreiro. Partindo de ideias tons - atreladas à inferioridade da construção dos templos religiosos afro-brasileiros e da mutabilidade do espaço, os representantes do Conselho Consultivo do Patrimônio Histórico e Artístico Nacional novamente reproduziram o preconceito derivado da inserção forçada do negro no Brasil: a cultura do negro e tudo que dela deriva possuiria pouco ou nenhuma importância. Trata-se aqui de comportamento comum ao subsistema de governo, ocupado por burocratas partidários das concepções tradicionais das políticas em curso, que representam valores sobre exercícios de poder.

O pedido de tombamento que representava a requisição de auxílio do Estado para preservação da cultura - que durante séculos 
foi perseguida pelos agentes estatais - transformou-se em mais uma luta de resistência, conforme afirma Velho (2012, p. 59): "Independentemente de aspectos técnicos e legais, o que estava em jogo era, de fato, a simbologia associada ao Estado em suas relações com a sociedade civil".

Esse autor também atenta para o fato de que o tombamento do primeiro monumento negro significava o reconhecimento do pluralismo sociocultural brasileiro e a reparação das perseguições sofridas pelos negros impelidas pelas elites e pelo Estado (VELHO, 2012). O caldo primitivo de políticas ferveu na Centésima Oitava Reunião do Conselho Consultivo do Patrimônio Histórico e Artístico Nacional, da Secretaria da Cultura, em 1984, em Salvador. Até esse momento, constava no processo o pronunciamento de antropólogos, artistas, representantes de terreiros, e representantes de órgãos públicos, favoráveis ao tombamento do Terreiro da Casa Branca. Porém, no momento da votação para aprovação do pedido de tombamento, os Conselheiros questionaram o tombamento, sugerindo a alternativa da garantia da posse do imóvel, o que resolveria a questão da insegurança ou a aplicação de outro tipo de intervenção estatal para auxiliar a comunidade, sem nenhuma especificação. Após longo debate, o tombamento foi aprovado com duas abstenções, um voto contrário, um voto pelo adiamento e três votos favoráveis ao tombamento. (VELHO, 2012).

A passagem relatada desnuda o processo de não-ação, abordado por Bachrach e Baratz (2011). Uma vez que o tema alcançou a agenda, os obstáculos foram impostos na discussão sobre alternativas. Comprova-se, assim, o incessante jogo de forças para obstruir a inserção de temas novos na agenda, a fim de manter o status quo. Por pequena margem de votos, a conquista da transposição do tema do tombamento dos terreiros para a agenda do governo quase foi derrotada na fase das alternativas. Considerando a teoria de Baumgarter e Jones (1993), talvez a imagem da política não tivesse sido transformada profundamente. Pois as alterações nos arranjos institucionais e as novas ideias que alcançaram o sistema ocupado pelas lideranças do governo ainda não pareciam suficientes para revolver os elementos simbólicos conservadores, plasmados nos subsistemas e na própria agenda sistêmica, de Cobb e Elder (1971).

Os elementos associados ao terceiro fluxo, que é o da política, permitem atentar para o papel do humor nacional da época, marcado 
DEIXA A GIRA GIRAR: proteção e preservação do patrimônio cultural das religiões afro-brasileiras

pelo desgaste dos anos de regime militar, com as denúncias de tortura e assassinatos e o declínio do discurso do milagre econômico, dando início ao período de transição política no governo do General João Figueiredo, no período de 1979 a 1985 (RUBIM, 2007; PEREGRINO, 2012). Após longos anos de repressão, havia no país ambiente favorável para a luta contra o autoritarismo, conservadorismo e discriminação. As forças organizadas representaram papel importante para a política de preservação do patrimônio, pois a organização dos movimentos sociais negros e das associações ligadas aos terreiros de candomblé se fortaleceu, tornando-os mais atuantes. Kingdon (1995, 2006a, 2006b) explica que, na política, tende-se a seguir o consenso, evitando conflito. Nesse ambiente, havia consenso simbólico favorável para a preservação dos terreiros. Ou seja, a fragilidade do governo militar destravou impedimentos para a luta dos movimentos negros.

Mas a oportunidade dessa fragilidade só foi explorada porque contou com a ação de empreendedores de politicas e atores visíveis e invisíveis no processo de abertura da agenda. No processo do tombamento dos terreiros, entre os atores invisíveis pode-se apontar o Egbé Iyá Nassô,o coordenador do projeto MAMNBA, os movimentos e entidades negras, entidades empenhadas na defesa dos direitos humanos, e o antropólogo e parecerista Gilberto Velho. Todos esses contribuíram no fluxo de alternativas.

Conforme o parecerista, a aprovação do tombamento do Terreiro da Casa Branca foi resultado da ação conjunta dos órgãos federais SPHAN e Pró-Mémoria, de diálogos com outras esferas governamentais, Estado da Bahia e Prefeitura Municipal de Salvador, um grupo de conselheiros da SPHAN, o Secretário de Cultura do MEC, os movimentos sociais, com a participação ativa de artistas, intelectuais, jornalistas, políticos, lideranças religiosas, pesquisadores e a comunidade interessada, e demais setores da sociedade civil, ou seja, envolveu diversos atores (VELHO, 2012).

Assim, os atores visíveis aqui presentes se conciliam com a figura dos empreendedores de políticas, agentes essenciais para amarrar os três fluxos, contribuindo com a abertura da janela de oportunidade da mudança. Foram eles: Aloísio Magalhães, ex-secretário de cultura do MEC, "[...] entusiasta do projeto e grande amigo da comunidade da Casa Branca." (SERRA, 2005, p. 179); o advogado, jornalista, professor, escritor, gestor de inúmeras institui- 
ções públicas, inclusive a de secretário de cultura do MEC, Marcos Vinicius Vilaça, também entusiasta da proposta; o economista, político, presidente da Bahiatursa e gestor de outras instituições públicas, prefeito de Salvador Manoel Castro, que, em 1985, assinou o decreto de desapropriação do imóvel onde estava situado o terreiro; por fim, o antropólogo, escritor e militante Ordep Serra. Esses atores investiram e souberam aproveitar e criar oportunidades que resultaram na proposta da preservação dos Ilês Axés e, especificamente, no tombamento provisório do terreiro da Casa Branca, em 1984, e definitivo, em 1986.

A janela se abriu para a questão da preservação dos Ilês Axés a partir da convergência dos fluxos de problemas, de soluções e político, com forte participação dos atores visíveis e invisíveis citados. Foi preciso aproveitar a policy windows, posto que o Terreiro da Casa Branca foi tombado provisoriamente em 1984 e definitivamente em 1986, comprovando a tese de Kingdon de que as janelas são transitórias. O próximo tombamento definitivo de terreiro no Brasil - do Ilê Axé Opô Afonjá - só ocorreu em 2000.

Há lapso temporal entre um tombamento e outro, e geralmente, longo período de análise processual, havendo concentração de tombamentos no ano de 2005. Nessa época foi realizado o tombamento definitivo dos terreiros Ilê Axé Iyá Omim Iyamassê (Gantois), Manso Banduquenqué (Bate Folha) e Casa Grande de Minas ou Casa das Minas Jeje ou Querebentã de Zomadonu.

Portanto, o ambiente político com a assunção de Luiz Inácio Lula da Silva em 2003, à Presidência da República, e a criação da Secretaria de Direitos Humanos (SDH) e da Secretaria Especial de Políticas de Promoção da Igualdade Racial (SEPPIR), com status de Ministério no mesmo ano, possibilitou a abertura de uma nova janela para a entrada do problema da preservação dos espaços religiosos na agenda governamental, permitindo o tombamento definitivo de três terreiros no mesmo ano, com processos que já duravam de quatro a cinco anos.

\section{CONCLUSÃO}

O Estado e o direito durante longo período foram utilizados como elementos de dominação, servindo ao projeto hegemônico de economia, sociedade e religião trazido pelos portugueses. Apesar da perseguição sofrida pelos negros, o seu legado alcançou a socieda- 
DEIXA A GIRA GIRAR: proteção e preservação do patrimônio cultural das religiões afro-brasileiras

de brasileira contemporânea através dos espaços de religiosos afro-brasileiros, que são verdadeiros guardiões das tradições, identidade, memória e cultura do povo que chegou ao país como seres escravizados e que necessitaram ressignificar suas práticas e estruturas sociais para sobreviver e manter vivas as tradições trazidas do solo africano.

A preservação dos terreiros de candomblé, através do tombamento, começou a ser requisitada na década de 1980, e até 2014 pelo menos 18 espaços religiosos afro-brasileiros no Estado da Bahia requisitaram a proteção estatal no âmbito federal.

O estudo dos processos de tombamentos demonstra que ainda há dificuldade para que a questão da preservação dos Ilês Axés conquiste a agenda governamental. Houve janelas de oportunidades em 1986, 2000, 2005, 2008, 2013, 2014 e 2015, mas na verdade poucos terreiros são tombados de forma definitiva pelo IPHAN; em todo o Brasil, apenas nove estão nessa condição.

Quando os terreiros requisitam o tombamento, o principal objetivo é que o Estado garanta a preservação do espaço físico e a segurança social dos egbé, possibilitando a continuidade das manifestações religiosas dos seus antecepassados.A política de tombamento, na forma como tem sido executada, tem direcionado a preservação do patrimônio cultural apenas para terreiros de candomblé, excluindo as demais religiões afro-brasileiras que também foram constituídas por brasileiros que contribuíram para a formação do país.

A análise do processo de tombamento do Terreiro Casa Branca expõe as inúmeras dificuldades no reconhecimento da importância dos negros no processo de formação da sociedade brasileira. Verifica-se que o impulso para a expansão da concepção de valor cultural e artístico sucedeu em dois governos autoritários, buscando conquistar legitimidade. Essas janelas de oportunidade dispuseram de atores engajados dentro e fora do governo, cujas ações desorganizaram, de alguma forma, os princípios de desigualdade hierárquica que constitui a estabilidade do subsistema de governo, ocupado por uma burocracia, enredado em concepções de cultura e arte muito influenciadas por valores comuns aos padrões europeus. Vale ressaltar que esses governos autoritários introduziram atores incomuns na máquina pública, não enredados com as imagens conservadoras das políticas de cultura até então praticadas. Mas se verifica que as conquistas não se sustentam por longo período, sendo revisadas nas ges- 
tões seguintes. Essa fragilidade aponta para a pouca porosidade entre os movimentos de abertura ocorridos nessas gestões autoritárias e a máquina burocrática, o subsistema, conservador. $\mathrm{O}$ autoritarismo que marcou essas gestões alude à dificuldade de participação política da sociedade, sobretudo das classes populares, como os movimentos negros. Assim, a potência dessas vitórias é restrita, pois o próprio povo de santo tem pouco poder para influenciar as ações de governo. E com o crescimento da bancada evangélica no Congresso Nacional e nos espaços de poder, os avanços para garantias de direitos constitucionais do povo de santo são cada vez mais escassos, ocorrendo a elaboração de leis que perseguem os adeptos, e a judicialização quanto à sacralização de animais nos rituais; o caso aguarda decisão do Supremo Tribunal Federal (STF).

Mas a CF de 1988 traduz um período de maior participação política e poder popular. As conquistas legais culminaram na criação de órgãos governamentais empenhados no reconhecimento da importância dos negros e das religiões afro-brasileiras na constituição do país, a partir da primeira metade do século XXI. Todavia, os problemas com o subsistema persistiram, manifestando-se nas dificuldades para a implementação das novas concepções que orientavam a ação governamental. Alguns exemplos são a exigência de documentos inviáveis para a maioria dos terreiros, como os que exigem personalidade jurídica e regularização fundiária do imóvel. Destaque-se, ainda, a forma de ação do IPHAN e de órgãos de fiscalização municipais, a exemplo da morosidade na análise e negativa aos pedidos de reforma financiada pelo próprio terreiro sem a realização de nenhuma visita técnica. Além do mais, é comum que o IPHAN limite sua ação à inscrição do bem no Livro do Tombo, sem atuar para a segurança social da comunidade do terreiro tombado. $\mathrm{O}$ tombamento garante a proteção do espaço físico dos terreiros, pelo menos formalmente. Porém, a continuidade do terreiro e das manifestações culturais nele existentes, não depende apenas da garantia do espaço para realização do culto. Assim, é preciso garantir a proteção estatal para os diferentes espaços religiosos afro-brasileiros, assegurando a diversidade de culto e nações, proteger as músicas, os orikis ${ }^{12}$, as danças, as palavras e outros elementos do patrimônio imaterial dos Ilês Axés, e efetivar ações que garantam a segurança social e os direitos dos adeptos de todas as religiões afro-brasileiras.

A preservação e proteção dos espaços religiosos afro-brasileiros e a segurança social dos adeptos mobilizou vários setores sociais 
DEIXA A GIRA GIRAR: proteção e preservação do patrimônio cultural das religiões afro-brasileiras

em busca do tombamento do primeiro monumento negro na década de 1980. Após mais de 30 anos, desde o início da política cultural, os espaços religiosos afro-brasileiros ainda são alvo de perseguição, depredação e demais formas de violência. No ano de 2017 a mídia apresentou diversos casos de terreiros queimados, de imagens e espaços de culto violados, assassinato de adeptos de religiões afro-brasileiras por motivo religioso e lesão ao direito à liberdade religiosa (perseguição/assédio religioso no ambiente de trabalho, xingamento nas ruas e estabelecimentos, preterição nos atendimentos em postos de saúde, escolas, etc.).

A fragilidade das alternativas na implementação e consolidação das políticas que reconhecem a importância dos negros no processo de formação da sociedade brasileira reflete a persistência de elementos autoritários, hierarquizantes e preconceituosos no governo, no Estado e na sociedade. Os violentos ataques praticados recentemente aos terreiros e ao povo de santo em todo o país indicam que a luta para converter esses temas em questões públicas ainda está longe de uma vitória robusta. Muitos setores do Estado e parte da sociedade parecem insistir na invisibilidade da relevância da contribuição dos negros e de sua cultura para identidade brasileira. Assim, a noção de nação ainda é feita a partir dos bens do período colonial, apesar dos novos paradigmas trazidos pela Constituição de 1988 que valoriza o pluralismo e a diversidade cultural.

\section{REFERÊNCIAS}

ALBUQUERQUE JÚNIOR, D. M. de. Gestão ou Gestação da Cultura: algumas reflexões sobre o papel do Estado na produção cultural contemporânea. In: RUBIM, A.; BARBALHO, A. (Orgs.). Políticas Culturais no Brasil. Salvador: EDUFBA, 2007. p. 61-86. (Coleção Cult).

BACHRACH, P.; BARATZ, M. Duas faces do poder. Revista de Sociologia Politica, Curitiba, v. 19, n. 40, p. 149-157, out. 2011.

BAUMGARTER, F. R.; JONES, B. D. Agendas and instability in American politics. Chicago, University of Chicago Press, 1993.

BRASIL. Constituição da República dos Estados Unidos do Brasil. Brasília, DF, 1891. Disponível em:<http://www.planalto.gov.br/ ccivil_03/Constituicao/Constituicao91.htm>. Acesso em: 27 jun. 2014. 
Constituição Política do Império do Brasil. Brasília, DF, 1824. Disponível em: $<$ http://www.planalto.gov.br/ccivil_03/ constituicao/constituicao24.htm>. Acesso em: 27 jun. 2014.

. Supremo Tribunal Federal. A Constituição e o Supremo. 3. ed. Brasília, DF: Secretaria de Documentação, 2010.

CHEHOUD, H. S. Q. A liberdade religiosa nos estados modernos. São Paulo: Almedina, 2012.

CHUVA, M. Entre vestígios do passado e interpretações da história: introdução aos estudos sobre patrimônio cultural no Brasil. In: CUREU, S. et al. (Coord.). Olhar multidisciplinar sobre a efetividade da proteção do patrimônio Cultural. Belo Horizonte: Fórum, 2011. p. 37-49.

COBB, R. W.; ELDER, C. D. The Politics of Agenda-Building: an alternative perspective for modern democratic theory. Journal of Politics, [S. 1.], v. 33, n. 4, p. 892-915, nov. 1971.

; ROSS, J.-K.; ROSS, M. H. Agenda Building as Comparative Political Process. The American Political Science Review, [S. 1.], v. 70, n. 1, p. 126-138, mar. 1976.

CRISTIANI, C. V. O direito no Brasil colonial. In: WOLKMER, C. Fundamentos de história de direito. 3. ed. rev. e ampl. Belo Horizonte: Del Rey, 2005. p. 295-309.

INSTITUTO DO PATRIMÔNIO HISTÓRICO E ARTÍSTICO

NACIONAL. Processo de Tombamento do Ilê Axé Iyá Nassô Oká (Terreiro da Casa Branca). Processo n 1.067-T-82. Brasília, DF, 1982.

KINGDON, J. Agendas, alternatives and public policies. New York: Longman, 1995.

PEREGRINO, M. da C. SPHAN/Pró-Memória: abertura política e novos rumos para a preservação do patrimônio nacional. Revista Confluências Culturais, Joinville, v. 1, n. 1, p. 86-100, set. 2012. Disponível em: $<$ http://periodicos.univille.br/index.php/RCC/article/ view/357/239>. Acesso em: 19 out. 2014.

PINHO, O. S. de A. O mundo negro: hermenêutica crítica da reafricanização em Salvador. Curitiba: Progressiva, 2010.

QUEIROZ, H. F. O. G. A proteção jurídica das "Pequenas Áfricas" no ordenamento constitucional brasileiro: o registro de lugar como instrumento hábil a proteção dos terreiros de candomblé? In: ENCONTRO INTERNACIONAL DE DIREITOS CULTURAIS, 2., 2013, Fortaleza. Anais... Fortaleza, 2013: UNIFOR, 2013. Disponível 
DEIXA A GIRA GIRAR: proteção e preservação do patrimônio cultural das religiões afro-brasileiras

em: $<$ http://www.direitosculturais.com.br/download.php?id=94>. Acesso em: 18 ago. 2014.

RIBEIRO, M. Liberdade religiosa: uma proposta para debate. São Paulo: Editora Mackenzie, 2002.

RUBIM, A. A. C. Políticas culturais no Brasil: tristes tradições, enormes desafios. In: ; BARBALHO, A. (Orgs.). Políticas Culturais no Brasil. Salvador: EDUFBA, 2007. p. 11- 36. (Coleção Cult).

SÁ, T. R. B. T. Códigos de Posturas Municipais como instrumentos normativos da produção de novas lógicas territoriais: estudo de caso do Centro Histórico de Salvador. Percurso: Sociedade, Natureza e Cultura, Curitiba, v. 11, n. 1, p. 273-289, 2011.

SANTOS, E. F. O poder dos candomblés: perseguição e resistência no Recôncavo da Bahia. Salvador: EDUFBA, 2009.

W. C. da S. Políticas públicas de reafricanização: tombamento dos terreiros de candomblé no Estado da Bahia. 2015. $236 \mathrm{f}$. Dissertação (Mestrado em Políticas Públicas e Segurança Social) Universidade Federal do Recôncavo da Bahia, Cruz das Almas, 2015.

SERRA, O. Monumentos Negros: uma experiência. Revista AfroÁsia, Salvador, n. 33, p. 169-205, 2005. Disponível em: $<$ http://www. afroasia.ufba.br/pdf/afroasia33_pp169_205_Ordep.pdf $>$. Acesso em: 15 nov. 2014

SILVA NETO, M. J. Proteção constitucional à liberdade religiosa. 2. ed. São Paulo: Saraiva, 2013.

SILVA, J. A. Ordenação constitucional da cultura. São Paulo: Malheiros, 2001.

SODRÉ, J. Da diobolização à divinazação: a criação do senso comum. Salvador: EDUFBA, 2010

VELHO, Gi. Patrimônio, negociação e conflito. In: AMORIM, C. A. et al. Políticas de acautelamento do IPHAN para templos de Culto afro-brasileiros. Salvador: IPHAN, 2012. p. 55- 69.

ZAMBUZZI, M. (2010) O espaço material e imaterial do candomblé na Bahia: o que e como proteger? 2010. 142 f. Dissertação (Mestrado em Arquitetura e Urbanismo) - Universidade Federal da Bahia, Salvador, 2010. Disponível em: $<$ https://repositorio.ufba. br/ri/bitstream/ri/12075/1/Disserta\%C3\%A7\%C3\%A3o\%20-\%20 Mabel\%20Zambuzzi.pdf>. Acesso em: 19 set. 2014. 


\section{ZANDONADE, A. O tombamento à luz da Constituição Federal de} 1988. São Paulo: Malheiros, 2012.

\section{Notas}

1 Os dados sobre tombamento de terreiros apresentados nas discussões são baseados no texto da dissertação apresentada ao Mestrado Profissional em Gestão de Políticas Públicas e Segurança Social, da Universidade Federal do Recôncavo da Bahia, de Walkyria Chagas da Silva sob a orientação da professora Doutora Rosy de Oliveira. A pesquisa foi financiada pela Fundação de Amparo à Pesquisa do Estado da Bahia

2 Este artigo se concentra nos processos de tombamento pela esfera federal, embora o governo do Estado da Bahia também tenha realizado tombamento de terreiros por meio do Instituto do Patrimônio Artístico e Cultural da Bahia (IPAC), cujo primeiro pedido foi efetuado em 1989, tendo sido concluído em 2004.

3 Nome utilizado para identificar os espaços de vivência das tradições africanas no Brasil, outro nome utilizado é Pequenas Áfricas. (PINHO, 2010; QUEIROZ, 2013).

4 O referido tratado não consta no Portal da Legislação do Governo Federal.

$5 \mathrm{Na}$ área jurídica costuma-se dividir o mundo em ser e dever-ser, o ser relaciona-se ao mundo dos fatos e dever-ser é relacionado ao mundo normativo, ao que deveria ser a partir das determinações legais.

6 Tânia Sá (2011, p. 277-282), aos estudar os Códigos de Posturas de Salvador, relata que os Códigos de Postura designavam regras de convivência em sociedade, assim, "A Metrópole portuguesa recorria a esses códigos com o intuito de impor a autoridade e zelar pela ordem e 'bons costumes' nas colônias que estavam sobre a sua jurisdição. [...] Códigos de Posturas, que compreendiam normas de âmbito local que interferiam diretamente, não somente nos planos, reformas e na legislação urbanística, mas também nas relações sociais de todos os moradores da urbe. Além da moralização dos costumes, das ações de controle social e da normatização dos espaços, o discurso modernizador higienista procurou empreender ações voltadas para a 'desafricanização' dos costumes que serviam como representação do atraso".

7 Os possíveis sistemas de relação entre a Igreja e o Estado são: a confusão, a união e a separação. Na confusão o Estado se confunde com a religião, e o poder é exercido conjuntamente. Na união há alguns pontos de contato entre o poder religioso e o poder estatal. Já na separação, o Estado e a Igreja são independentes, o Estado é denominado laico. (CHEHOUD, 2012).

8 A Constituição atual reafirma a separação entre o Estado e a Igreja e garante a liberdade religiosa nos incisos VI e VII, do art. $5^{\circ}$. Os incisos citados asseguram as três dimensões do direito à liberdade religiosa, quais sejam, a liberdade de crença, a liberdade de culto e a liberdade de organização religiosa. A liberdade de crença garante o direito de crer naquilo que satisfaça os anseios espirituais ou em não crer em nada relacionado a questões religiosas/espirituais. A liberdade de culto assegura o livre exercício do culto e das liturgias. E por fim, a liberdade de organização religiosa, possibilita a criação de segmentos religiosos. (SILVA NETO, 2013).

9 Diante dos diversos significados atribuídos a palavra cultura, e não sendo o objeto do presente trabalho conceituar cultura, mas trazê-la para discussões pela sua ligação com o tema central, optou-se por centrar a temática em questões jurídicas, com especial ênfase para os conceitos trazidos pela CF de 1988.

10 Segundo Costa (2011), a CF de 1988 foi a primeira Constituição brasileira a utilizar o termo direitos culturais.

11 Termo nagô que significa sociedade, associação ou comunidade.

12 Invocação, saudação ou louvação direcionada aos orixás, antepassados e outros elementos de compõem a tradição Yorubá. 